\title{
Mensaje del Presidente de la Confederación Panamericana de Medicina del Deporte (COPAMEDE)
}

\author{
Carlos Pablo D'Angelo
}

Este mensaje puede ser la razón para hacer un discurso de circunstancias o para realmente marcar las líneas ideológicas más importantes que puedan trazarse con respecto a los temas que luego debatiremos.

He elegido esta última forma, que creo, más comprometida si se quiere, pues mis largos años en esta actividad, me permiten marcar líneas ideológicas y abrir de esta manera la discusión.

El deporte y la medicina, o la medicina y el deporte, o la medicina del deporte en la vida del hombre; veamos esto último.

El hombre tiene una actividad que lo dispersa en múltiples ocupaciones, su trabajo, su familia, su actividad intelectual, su deseo de trascender, su ocio creativo, etc.

Si observamos la vida humana, podemos concluir que un tercio de la misma, la ocupa el hombre en aprender la cultura heredada de sus mayores. El hombre pasa 20 años aprendiendo un depósito cultural que junto con su carga genética van a constituir la esencia de la conducta humana.

Otro tercio de la vida la ocupa el hombre en trasvasar lo recibido a sus hijos. Y aquí surge la primera reflexión. El hombre puede, a diferencia de otras especies, delinear de alguna manera cómo será su futuro; lo podemos prever, planificar, tratar de buscar los modelos necesarios para las situaciones que vendrán.

Prever es, en este momento, buscar que perfil jugarán de manera armónica la medicina y el de porte en el siglo XXI.

Qué perfil tiene nuestra especialidad? Cuál el que pretendemos que nuestra especialidad tenga?

Una manera de contestar este interrogante, es bucear en la historia para conocer cuál era la relación entre el deporte y la medicina en los albores de nuestra civilización.

Podríamos decir que la importancia del deporte en la formación humana comienza con los griegos.

Para ellos, la naturaleza por si sola, tiende a lo bello y lo perfecto. Una alma bella esta siempre encerrada en un cuerpo bello, es deber del hombre cultivar su espíritu y cuidar su figura a través del deporte.

Esta forma de interpretación implica una función pedagógica del deporte. El deporte sirve no solo para conformar el aspecto exterior del ser humano, sino que es parte de la educación del hombre. Cuando se le enseña al hombre a compe- tir, se le enseña que la vida es competencia, pero también, se le enseña que una de las condiciones básicas de la competencia humana es el limite ético, y que la infracción a la regla es un acto desleal. Aquel individuo que no transgrede las reglas deportivas será, probablemente, un juez no venal, el medico que cumplirá con su deber, o el operario que irá mas allá de sus obligaciones en sus tareas.

Estas ideas se han ido poco a poco disvirtuando por la crisis de valores que ha caracterizado a casi todo el siglo $\mathrm{XX}$. Ya no se establecen limites éticos a las actividades humanas, o por lo menos se los cuestiona. El deporte no ha sido ajeno a estos cambios y ésto, ha llevado a que la práctica deportiva, esté perdiendo ese aspecto formativo que constituia una de sus características fundamentales.

Al mismo tiempo, encontramos la medicina, a la que debemos considerar como la ciencia de la salud y no de la enfermedad. Y si nos preguntáramos que es la salud, llegaríamos quizá a la misma definición que dio, 600 años antes de Cristo Alcmeón de Crotona. "La salud es un estado de isonomía, es decir de equilibrio de opuestos, ganas de descansar y ganas de trabajar, ganas de divertirse y ganas de estudiar, etc. Y cuando se llega a ese maravilloso e inestable equilibrio podemos decir que se esta en estado de salud. La salud es lucha, ya que de ese estado se entra y se sale permanentemente tal como lo preconizan algunas escuelas actuales de epidemiología con el concepto dinámico del estado de salud - enfermedad.

Por esa misma época, nos encontramos en los inicios de la ciencia occidental, que se basa en dos concepciones muy claras. La primera de ellas, de origen jónico (siglo V y VI antes de Cristo) establece que la lógica del pensamiento humano es similar al orden lógico de la naturaleza, y en consecuencia la mente humana es capaz de entender dicho orden. La otra, del atomismo de Demócrito y Leucipo, que dice que nada se produce sin causa y efecto, es decir que hay un orden natural desarrollado merced a causas y efectos. Esto lleva a la concepción de que toda la naturaleza está interrelacionada. La naturaleza es un manto que cubre todo el universo, siendo el hombre el emergente mas maravilloso y perfecto de todas las creaciones del cosmos.

Esta relación entre el hombre y la naturaleza hace que el concepto de salud lleve implícito una responsabilidad colec- 
tiva y compartida que aparece en cada una de nuestras acciones, ya que las mismas influirán sobre el todo.

Dejando de lado estas ideas del mundo antiguo, vemos todavía que en numerosas áreas de formación humana, se sigue participando de la idea de que todo lo que el hombre haga tiene influencia sobre el entorno cercano y alejado.

Nos encontramos en el siglo XVI con el pedagogo y pensador ingles Roger Ascham, que indica que para que un estudiante universitario ingles pueda tener un desarrollo armónico y adecuado, que le permita convertirse en caballero, debe tener también un cuerpo armónico y adecuado. Para ello, deberá practicar deporte porque además el mismo es una actividad formadora para la vida. Aparece así el deporte en las universidades inglesas, que luego se extenderá en el resto de Europa. Pero cual es el deporte que Ascham quería para sus universidades? El único aséptico, según su concepción era la arquería. Vemos pues, que para este pedagogo, el deporte no es solo formativo del cuerpo sino también del alma.

Si retornamos al concepto griego de que un cuerpo bello significa un alma bella, nos damos cuenta de que esto simplemente se basa en la unidad de la naturaleza.

Cuando la naturaleza de por si produce algunas expresiones exteriores imperfectas, no significa ello un estigma inmediato con respecto a las cualidades morales de un individuo. Es sabido que quizá el griego más feo de Atenas, el más pequeño y el más contrahecho era nada menos que Sócrates. Sin embargo, era admirado por todos sus connacionales ya que Sócrates era capaz de realizar campañas militares o andar casi desnudo y descalzo sobre la nieve, y de ser un héroe dentro de sus posibilidades para defender la libertad de su país.

Por aquellos años también la actividad física de cualquier tipo, aun el juego del niño, es defendida para la formación humana por pedagogos separados en la historia y por espacios territoriales. Podríamos citar a Andreas Commenio en el 1600 en Bohemia y Victorino Da Feltre en su casa Gioiosa en el 1500 italiano, por primera vez, se piensa que el niño puede aprender jugando, y en consecuencia que ese juego es parte del proceso pedagógico.

Vemos pues que el deporte, como parte integrante de la vida será también parte integrante de la salud. Es decir, la medicina aplicada al deporte y el deporte coadyuvan a una formación no solo de un cuerpo armonioso sino también de una alma pura y limpia.

Si nosotros cuestionamos algunos aspectos del siglo XX, tenemos que decir también que en este siglo los resultados cuentan a veces mucho más que los medios para lograrlos. Nos encontramos entonces con otra vertiente de la medicina del deporte aplicada a mejorar el rendimiento deportivo, ya no buscando ese equilibrio que querían los antiguos y que trascendía para ellos como la noción ideal de salud, sino procurando el éxito en la competencia.
Nos encontramos pues con dos ramas de la medicina del deporte: la que busca salud y la aplicada a la alta competición, ramas que no se contraponen, que no son opuestas, pero que se diferencian en el enfoque del hombre. Una de ellas aplicada, a la formación humana, y otra, aplicada al alto rendimiento y al resultado, aun a veces, a costa de producir problemas de salud en el momento o a posteriori en los deportistas, ya sea salud física o mental, y que puede llevar en ciertos casos a la deformación del deportista como persona.

Si hablamos de medicina del deporte aplicada a la salud cabe preguntarse salud para qué? Es la salud un fin en sí mismo o un medio para conseguir algo? Si la salud fuera un fin en sí mismo podríamos poner en un pie de igualdad a un buey y a un hombre, y aun mas, como un buey tiene mas fuerza, mejores funciones vegetativas, etc., podríamos decir que un buey es mas sano que un hombre.

Si la salud es un medio para, entonces la salud humana es totalmente distinta, porque el hombre es un ser pensante y si bien tiene la biología común con el buey, tiene ese bagaje psicológico y social que lo hace tan diferente de los animales. En el hombre, la salud es un componente importante de las calidades de vida humana. La salud, la vivienda, la educación, la seguridad, la libertad, el ocio recreativo, la alimentación adecuada, etc., son componentes interdependientes y necesarios de la calidad de vida, pues si uno de ellos falta, la misma se degrada. La salud es un componente fundamental en la calidad de vida del hombre ya que evita las limitaciones que el ser humano tiene. Un hemipléjico no toca el violín, un ciego no es miniaturista, un neurótico no puede ser un gran artista con plena libertad de creación sino condicionado por su problemática, etc. Vale decir que la salud humana es un medio para lograr fines, ya que el hombre, al no sentirse limitado, puede elegir en plena libertad su modelo de vida, y puede ser en consecuencia plenamente feliz. La salud es un medio entonces al servicio de la libertad.

En este contexto, la medicina del deporte y el deporte se constituyen en un elemento formativo.

La libertad humana significa posibilidad de elección y para que esta sea posible el hombre debe tener una información suficientemente clara para que cada uno con las escalas de valores y juicios personales elija entre las distintas alternativas que se le presenten.

Esta escala de valores es la que tiende a formar el deporte y la medicina del deporte cuando tiene la salud y los aspectos formativos como objetivo.

Pero esta escala axiológica se altera cuando en la misma se coloca un valor único, el éxito, que lleva a que un deportista con tal de ganar se enferme, que deforme su cuerpo o ponga en riesgo su vida.

Debemos pues tener en cuenta que la implicancia de nuestra especialidad no es solo técnica. Hay una responsabilidad moral del medico del deporte, ya que desde allí avala una 
serie de acciones donde el deportista puede ser ejemplo, víctima o victimario.

Qué resta esperar del futuro de nuestra especialidad? Iniciando el siglo XXI podríamos afirmar que, haciendo un balance ideológico del siglo actual, este ha quedado en deuda consigo mismo. El siglo XX se ha caracterizado desde el punto de vista de su ideología ética por desmitificar y destruir toda una serie de valores y conceptos que regían la vida humana. Pero sin lugar a dudas, ha quedado en falta ya que no logró establecer un nuevo código deontológico. Ese creo que constituye el primer gran desafío para el siglo que viene. El progreso tecnológico, cada vez mas importante y veloz, que debería ser aplicado exclusivamente a mejorar la calidad de vida humana, necesita ser condicionado por un nuevo código ético pues su ausencia puede hacer que el progreso científico no solo desmejore la calidad de vida, sino incluso llevarla a la destrucción.

La medicina del deporte en estos proyectos debe contribuir en su campo de acción a resaltar la práctica de actividades físicas como una actividad que contribuya al desarrollo biopsíquico del individuo y coadyuve a su inserción social. Desde esta perspectiva, la búsqueda de la salud como objetivo primario del deporte, sería coincidente con los fines de la medicina en general y de la medicina del deporte en particular.

En relación con la alta competencia, la medicina del deporte debe jugar un papel de enorme importancia ya que para alcanzar el éxito deportivo, muchas veces, se violan reglas básicas de la fisiología humana. Fundamentalmente, bregar por humanizar la alta competencia, tratando que la misma sea un ejemplo de lo que puede lograr el hombre a través de su esfuerzo creativo y armonioso. La medicina del deporte, tratará en este contexto los conocimientos médicos necesarios para lograr alcanzar la plenitud de la potencialidad humana. Mirado desde esta perspectiva, el atleta de alto rendimiento deberá también ser visto desde la óptica de la salud no solo durante sus años de competencia sino también en su futuro.

Lograremos quizá en este camino, que ni el atleta sea un enfermo potencial ni que el alto rendimiento se transforme en una patología en sí mismo al pretender transformar al hombre en una herramienta al servicio de la economía, del rendimiento o del éxito.

En síntesis creo que éste debe marcar la transición entre las concepciones médico deportistas del siglo que concluye y las que debemos construir para el que vendrá. Este es nuestro desafío. 